ISSN: 2162-3104 Print/ ISSN: 2166-3750 Online

Volume 8, Issue 2 (2018), pp. 742-768

(C) Journal of International Students

http://jistudents.org/

doi: 10.5281/zenodo. 1250377

\title{
How Do South American International Students Experience Student Life in Flanders? A Photo Elicitation Project
}

\author{
Qingchun Wang \\ KU Leuven, Belgium \\ Steffanie Leen \\ KU Leuven, Belgium \\ Karin Hannes \\ KU Leuven, Belgium
}

\begin{abstract}
Millions of tertiary international students are studying abroad, and the number of exchange students continues to increase. We explored experiences of South American students studying in a non-Anglophone context. A photo elicitation methodology was applied to support data collection. Five participants were asked to visualize their challenges in their adjustment in pictures. We conducted individual interviews where images were used as prompts to narratives. Data were analyzed using a thematic analysis approach. Three main themes were identified: socio-cultural adjustment, academic adjustment, and psychological adjustment. Our data suggest that adjustment processes do not automatically lead to an adaptation outcome. Individual factors such as students' acculturation strategies and coping mechanisms, and situational variables like social interaction and cultural discomfort affect their adjustment.
\end{abstract}

Keywords: adjustment, challenges, internationalization, photo elicitation, South America 


\section{INTRODUCTION}

In the year 2013, over 4 million tertiary international students were studying abroad (Organisation for Economic Co-operation and Development, 2015). Each year, an additional $7 \%$ of students are temporarily moving abroad for educational purposes due to a variety of provided stimuli (Organisation for Economic Co-operation and Development, 2015): First, the funding opportunities are very attractive. The Erasmus + programme, for example, has a budget of $€ 14.7$ billion for the period 2014 until 2020 (Altbach \& Engberg, 2014). Two thirds of the budget is devoted to scholarships for individual students studying abroad. Second, universities strongly attract overseas students and recommend domestic students to undertake a study or internship abroad. In the information sessions organized by universities and websites with relevant information for students considering studying abroad, numerous benefits are outlined. Some examples include the opportunity to study at a world-class university, make a difference, and add valuable asset to future career (KU Leuven, 2017a) or developing various skills and global competency (PennState College of Agricultural Sciences, 2007). Third, studying abroad is often portrayed as an enriching and meaningful experience, which is expected to enhance the competitiveness of the participating students in the future job market. It is assumed that when such stimuli are provided, the exposure to different cultural environments will create a learning curve in which students move from a period of adjustment to an adaption phase. Adaptation then means that at least part of the new culture is integrated in their knowledge schema. An example of a conceptual model that displays this logic is the one from Schartner and Young (2016) which will be discussed below.

\section{A Conceptual Model of International Student Adjustment and Adaptation}

Schartner and Young (2016) conducted two quantitative studies with 108 and 226 international students in UK respectively, using a mixed methods design of self-report surveys and individual semi-structured interviews. In the model based on these study findings, the authors propose three phases international students go through during their adjustment process: arrival, adjustment, and adaptation (see Figure 1). 

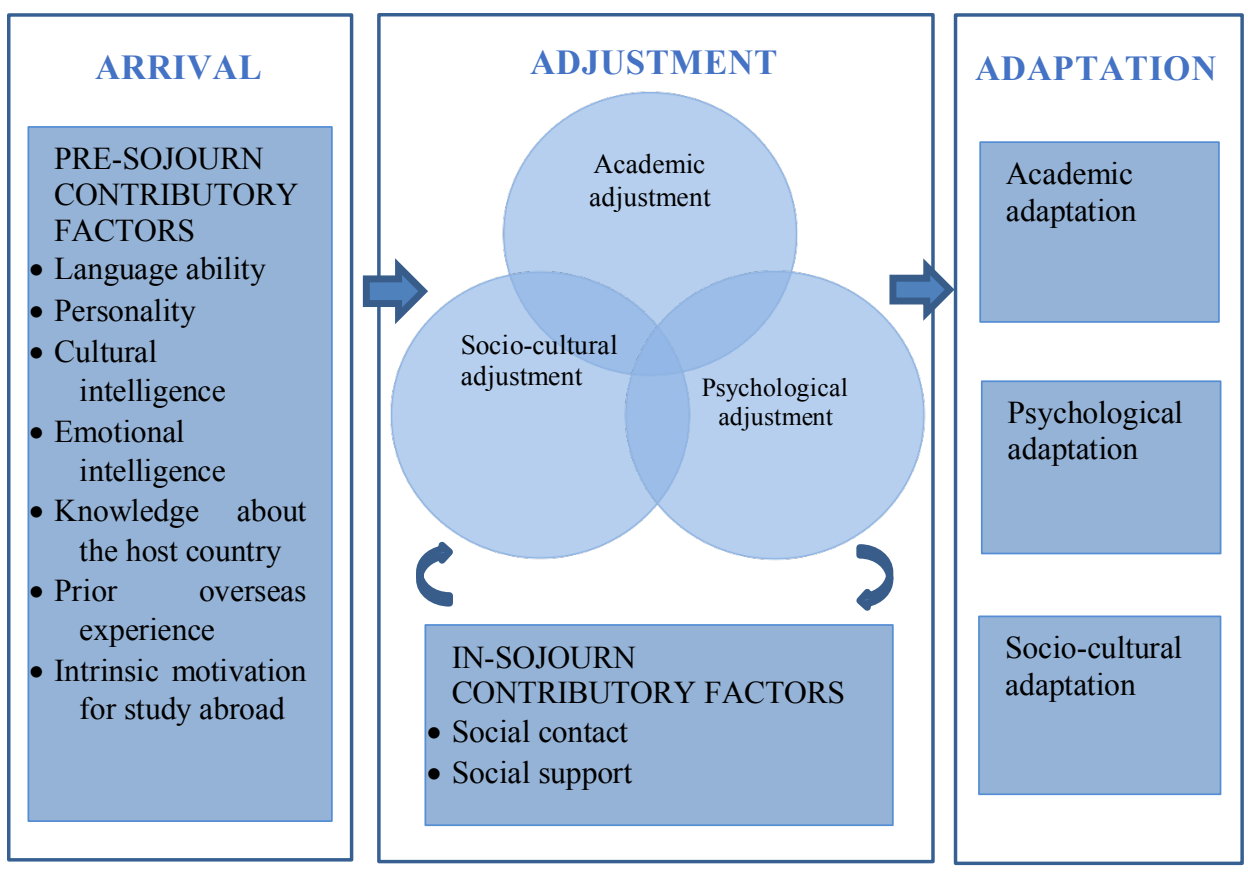

Figure 1. A Conceptual Model of International Student Adjustment and Adaptation, adapted from Schartner \& Young, 2016.

During the arrival and adjustment phases, there are many factors contributing to adjustment. The authors distinguish between pre-sojourn and in-sojourn contributory factors. The pre-sojourn factors refer to the dispositional factors or student sojourners' readiness for change. They may include language ability, personality, cultural intelligence (i.e. cultural empathy, open-mindedness, and social initiative), emotional intelligence, knowledge about the host country, prior overseas experience, and intrinsic motivation of studying abroad (Mesidor \& Sly, 2016; Schartner \& Young, 2016; Zhang \& Goodson, 2011). In-sojourn contributory factors impact on students' adjustment after their arrival. The degree of social contact with both host nationals and international students, and social support work as insojourn contributory factors which influence international students' successful adjustment to the foreign environment.

In this model (Schartner \& Young, 2016), adjustment is discussed from an academic, socio-cultural, and psychological perspective. Academic 
adjustment refers to adjustment to various demands in an educational setting, including different educational systems, teaching and learning styles. Socio-cultural adjustment is understood as "the ability to fit in and negotiate interactive aspects of the new culture" (Searle \& Ward, 1990, p. 450). Psychological adjustment is conceptualized as "affective responses to the new environment, including psychological well-being and satisfaction with life" (Schartner \& Young, 2016, p. 374). The three adjustment domains are interrelated, with pre-sojourn contributory factors acting on the adjustment and in-sojourn factors interplaying with the adjustment process. The last phase is adaptation, which represents the outcome of adjustment. It is the phase in which an individual becomes accustomed to the new environment. The model suggests that academic, socio-cultural, and psychological adjustment will automatically lead students into the phase of academic, socio-cultural, and psychological adaptation.

\section{Problem Statement, Research Objectives, and Questions}

The value of the framework is that it provides some clarity on factors that influence international students' adjustment processes and adaptation. However, it suggests that international experience is a very linear process. Does the adjustment process necessarily lead to adaptation for every student? Is the process of adjustment a more complex endeavor with a dynamic interaction between different factors? In this study, we will focus on the challenges, both in terms of opportunities and obstacles, in the everyday life of international students. We aim to deepen the understanding of adjustment experiences of international students through investigating the individual life stories using visual research method. Our primary objective is to examine different pathways of adjustment experiences and refine the model by means of identifying the mechanisms that push or pull students into different adjustment and adaptation patterns. The main research questions for the current study are as follows:

- Q1: What are the challenges that contribute to or hinder the adjustment experiences of international students?

- Q2: What are the potential pathways of international students' adjustment experiences? 


\section{The Case: South American International Students in Flanders}

Different cultural groups need to cope with different challenges abroad (Constantine, Okazaki, \& Utsey, 2004; Fritz, Chin, \& DeMarinis, 2008). The greater the cultural difference is between home and host society, the bigger struggles individuals might experience in their adjustment processes (Kagan \& Cohen, 1990). Compared with Western counterparts, non-Western international students are faced with significantly more integration problems related to social, emotional, and personal aspects (Rienties, Beausaert, Grohnert, Niemantsverdriet, \& Kommers, 2012). Qualitative research exploring the experiences of non-Western international students focuses primarily on Asian international students (Guillen \& Ji, 2011; Swami, Arteche, Chamorro-Premuzic, \& Furnham, 2010; Wang \& Hannes, 2014; Wang \& Mallinckrodt, 2006; Wei et al., 2007). In some studies, South/Latin American participants are represented in small number (Constantine et al., 2004; Lee \& Rice, 2007; Russell, Rosenthal, \& Thomson, 2010). Overall, there is a lack of studies targeting South American students, which is why we chose to work with this specific international student group.

So far, two qualitative studies have been conducted focusing on the adjustment experiences of international students in Flanders: Wang and Hannes (2014) investigated Asian students and Swarts (2012) studied African students. Although these studies took place in the same setting, some findings were similar while others divergent. For example, both studies addressed the theme of social connectedness, focusing on forming and maintaining social networks. However, under the category of sociocultural adjustment, sub-categories on cultural difference and socio-cultural adjustment strategies (including forming and keeping social networks, and engagement in activities in public places) were identified in the study conducted by Wang and Hannes (2014), while under the same category, quite different sub-categories appeared in the study of Swarts (2012): hospitality and social exclusion, finding one's roots as an African, and social connectedness and friendship. Investigating an additional cultural group studying in the same setting may bring in new perspectives and validate some of the previous findings. 


\section{RESEARCH METHOD}

This study applies a visual research method called photo elicitation. Photo elicitation is using photographs in interviews to trigger responses from participants. Photos "evoke deeper elements of human experiences than words alone" (Harper, 2002, p. 13). They help stimulate participants' memories, boost their ideas, and facilitate interpretation and theory (Roberts, 2011). Photos also enable researchers to capture certain emotions from the participants that are complex to express in words. In many cases, photos may relieve the pressure of the participants being questioned directly, create a safer atmosphere compared to traditional interview techniques, and improve the dialogue between researcher and respondents in a more symmetrical way (Collier, 1957; Kolb, 2008). In this project, participants take photos that reflect their experiences, perspectives, and understandings in regard to the research questions during the research process (Kolb, 2008). As English is not the native language of the participants in this study, they may feel more comfortable and better express themselves when photos are used to elicit conversations (Margolis \& Pauwels, 2012).

\section{Setting}

We chose the University of Leuven (KU Leuven) in the Flemish community of Belgium as our setting. Belgium is a country with three official languages and a complicated political structure. Education is organized by each of the three decentralized communities: the French, the Flemish, and the German community. In Flanders, a range of master programs are provided in English. However, Dutch, which is the official language of Flanders, is used in informal situations and may bring additional challenges to international students. Belgium has an incoming student mobility of $10 \%$, which is just above the average of the countries investigated according to Organisation for Economic Co-operation and Development (2015) annual report. KU Leuven, the largest university in Belgium, has official ties with many international partners, including South/Latin America. Joint actions include the Latin America Fund which supports promising collaborative projects, Erasmus Mundus Action 2 projects, and Sciences Without Borders. 


\section{Sampling and Research Population}

The recruitment for participants was carried out partly through an invitation on Facebook and partly through the support of different organizations of KU Leuven that offered us a spot in their newsletters. Participation was entirely voluntary. Among the ten participants initially agreeing to participate, five participants finished the whole research process. Known reasons for dropping out were as follows: returning to home countries for family reasons (two) and lack of English language skills (one). Among the remaining five participants, three came from Brazil, one from Ecuador, and another one from Peru. There were three female students and two males, aged between 21 and 35. Four students participated in master programs, and one enrolled in a doctoral program. They were registered in various faculties. By the time this study was conducted, participants all had lived in Flanders for at least six months, and planned to stay in Belgium for a further eight months to four years. More detailed information of the participants can be found in Table 1.

Table 1. Demographics of the Participants

\begin{tabular}{|c|c|c|c|c|c|}
\hline & Sex & Country & Age & Program & Faculty \\
\hline 1 & Female & Brazil & 21 & Master & $\begin{array}{l}\text { Faculty of Bioscience } \\
\text { Engineering }\end{array}$ \\
\hline 2 & Female & Ecuador & 35 & $\mathrm{PhD}$ & $\begin{array}{l}\text { Faculty of Psychology } \\
\text { and Educational } \\
\text { Sciences }\end{array}$ \\
\hline 3 & Male & Peru & 27 & Master & $\begin{array}{l}\text { Faculty of Economics } \\
\text { and Business }\end{array}$ \\
\hline 4 & Male & Brazil & 23 & Master & $\begin{array}{l}\text { Faculty of Engineering } \\
\text { Technology }\end{array}$ \\
\hline 5 & Female & Brazil & 33 & $\begin{array}{l}\text { Master } \\
\text { (internship) }\end{array}$ & $\begin{array}{l}\text { Faculty of Bioscience } \\
\text { Engineering }\end{array}$ \\
\hline
\end{tabular}

\section{Briefing the Participants}

The first meeting with the participants was in the form of an information session and interactive ethical session. In the information session, participants were informed of the goals, method, expectations, and target deadlines of the research project. In the ethical session, attention went 
to the formalization of a written consent and potential ethical pitfalls of taking and using pictures, such as portraying private issues that may cause shame or embarrassment (Hannes \& Parylo, 2014). Participants were actively involved in discussing strategies to overcome such pitfalls. Possible alternatives for shooting images of people were shooting when it is glimmering, using metaphors, and taking more distance from the subject. The participants joining the project in a later phase of recruitment were briefed individually by the researcher on the important information of both sessions.

\section{Data Collection}

The participants had around two months' time to take pictures. Only one person explicitly asked for more time. The assignment provided was to shoot pictures of challenges that they experienced as international students in Flanders. Both positive and negative experiences were identified. They could take as many pictures as they liked, but in the end, they had to select around ten to maximum fifteen pictures of each theme of opportunities and obstacles. The selected pictures were sent to the researcher a few days before the interview.

In an attempt to minimise the impact of personal experiences and bias in the data collection phase of the project and by means of a bracketing exercise, the pictures were examined and subjected to memo writing before the interview took place. The interviewer first answered all interview questions herself, in an attempt to create awareness about personal ideas that may potentially steer the interviews. It allowed her to position herself more neutrally during interviews with Latin-American students.

The semi-structured interviews with a length between one to twoand-a-half hours started with participants' general thoughts on the motives to pursue their studies in Belgium, and their personal evaluation of the research project itself. Afterwards each picture was discussed based on the questions which were used to probe the story of the picture. The main interview questions were the following: "What is the core idea in this picture? What message do you want to tell me? Which opportunity/obstacle are you picturing here?"

\section{Data Analysis}

We opted for a thematic analysis for the transcripts and images. Thematic analysis generates themes emerging from the embodied ideas in 
the interviews (Savin-Baden \& Major, 2013). The transcripts were first read several times. Core thematic lines were pulled from previous studies conducted in similar contexts and used as sensitizing concepts to structure initial findings. These were refined based on emerging content through an iterative process of coding and categorizing. Open coding took place on the level of interview paragraphs. A constant comparative analysis technique was used to classify codes with a similar meaning under broader categories identified across interviews. After several times' reviewing the categories, a final set of themes that presented the content of the transcripts and pictures best were decided (Howitt, 2010). A more detailed overview of the analysis method is provided in Table 2 .

\section{Table 2. Detailed Overview of the Steps of the Thematic Analysis}

\begin{tabular}{|c|c|c|}
\hline & $\begin{array}{l}\text { Familiarise } \\
\text { yourself } \\
\text { with data }\end{array}$ & $\begin{array}{l}\text { The researcher read and closely examined the transcripts } \\
\text { several times to familiarise with the transcripts of all } \\
\text { participants. By doing this, the researcher got a better } \\
\text { insight into the transcripts. }\end{array}$ \\
\hline 2. & $\begin{array}{l}\text { Generate } \\
\text { initial } \\
\text { codes }\end{array}$ & $\begin{array}{l}\text { In an open coding, initial codes were assigned to each } \\
\text { paragraph. The researcher chose to analyze by hand. It } \\
\text { allowed the researcher to be actually 'hands on' (Savin- } \\
\text { Baden \& Major, 2013). Because of working extensively } \\
\text { with the data, the researcher developed an intuitive feeling } \\
\text { with the data. }\end{array}$ \\
\hline & $\begin{array}{l}\text { Search for } \\
\text { themes }\end{array}$ & $\begin{array}{l}\text { In the search for themes, an axial coding took place first. } \\
\text { While coding, researcher constantly compared the axial } \\
\text { codes to search for connections with other codes and } \\
\text { thought about possible changes in codes. Then, when } \\
\text { retrieving all codes, the researcher interpreted the codes } \\
\text { and tried to find fitting themes in a first attempt. }\end{array}$ \\
\hline & $\begin{array}{l}\text { Review } \\
\text { themes }\end{array}$ & $\begin{array}{l}\text { By reinterpreting and reviewing the themes, the final } \\
\text { subthemes and main themes were created. This process } \\
\text { took most of the time because it was hard to create 'good' } \\
\text { themes that were not overlapping and that covered the best } \\
\text { ideas of the transcripts and pictures. }\end{array}$ \\
\hline & $\begin{array}{l}\text { Define and } \\
\text { name } \\
\text { themes }\end{array}$ & $\begin{array}{l}\text { After a few tries for reviewing the themes, the final themes } \\
\text { were decided. }\end{array}$ \\
\hline 6. & $\begin{array}{l}\text { Produce } \\
\text { the report }\end{array}$ & $\begin{array}{l}\text { The final main themes and subthemes were reported in the } \\
\text { findings section. }\end{array}$ \\
\hline
\end{tabular}




\section{FINDINGS}

The narratives and photos are presented in three main themes: socio-cultural challenges, academic challenges, and psychological challenges. Each theme has subcategories that focus on opportunities contributing to adjustment and obstacles hindering adjustment.

\section{Socio-Cultural Challenges}

Socio-cultural challenges refer to a combination of social and cultural elements (Ward \& Kennedy, 1993). The social dimension is associated with situations where people interact with each other (van Hoof $\&$ van Ruysseveldt, 2008). The cultural dimension refers to the "complex whole which includes knowledge, belief, art, morals, law, custom, and any other capabilities and habits acquired by people as a member of society" (Tylor, 1871, p. 1). We identified seven sub-categories under socio-cultural challenges: social interaction, engaging in activities, bureaucracy, transport, food and drinks, language, and environment.

\section{Social Interaction}

Interaction is described by van Hoof and van Ruysseveldt (2008) as the daily interaction and communication processes, micro worlds where people live in, the way they define and redefine situations, and the consequences for the development of their (personal) identity.

\section{Opportunities}

All five participants agreed that studying abroad was experienced as an opportunity for meeting new friends, especially people of their own nationality and international communities. Making international friends appeared to be quite easy, as they were described as more social than local students ( 3 out of 5 participants). Programs organized by the university were a good opportunity for students to meet friends and learn about local and various cultures. An example included the Buddy Program, with a local student volunteering as a buddy as a way to assist one or more international students to better integrate in Flemish student life (KU Leuven, 2017b).

Obstacles. Making local friends was experienced as challenging (3 out of 5). One obstacle hindering students' connectivity with local friends was that Flemish students went back to their home cities every weekend (2 out of 5). Also, the reserved mentality and the way social relations of Belgian students were built played a significant role. South American 
students felt that Belgians were harder to get to know than South Americans, particularly in the early phase of their relationships (2 out of 5). However, "when someone actually starts considering you as a friend, it is a link that they will try to maintain" (Participant 3). One participant stated that sticking to friends from their own culture was experienced as restricting them from meeting friends from other nationalities.

\section{Engaging in Activities}

\section{Opportunities}

We further divided engaging in activities into four sub-categories: participating in cultural events and sports, exploring different cities, enjoying lazy afternoons, and developing hobbies or passions. Four participants talked about various cultural events they attended (e.g. art exhibitions) and sports clubs they joined (e.g. golf club). Some spent part of their spare time on international activities organized by Erasmus Student Network (3 out of 5). These activities provided them opportunities to explore new things, especially things they may not be able to experience in their home countries, such as ice skating.

Secondly, exploring different cities (e.g. Gent, Bruges, Brussels, and Paris) seemed to be an important element of their leisure time (4 out of 5). For one participant, it was experienced as an exceptional chance to visit cities that were on her "bucket list" (see Figure 2). It was visually portrayed in twelve pictures, among which a lot of historical cities and buildings were depicted (4 out of 5). Participants were generally interested in knowing the story behind the famous statues and buildings, such as the famous Belgian icon 'Manneken Pis', and the story of a castle someone bumped into by accident. Participants actively discovered local festivities and traditions, which were celebrated differently compared to their home countries ( 3 out of 5). Important events encompass Christmas in winter, Sinterklaas (focusing on children), and carnivals.

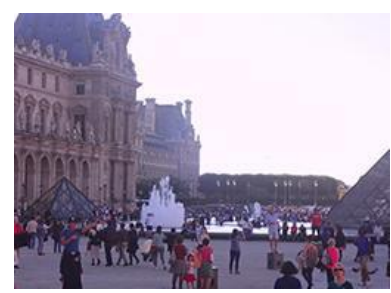

Figure 2. A Dream. "From when I was a child, I always think... one day, I will visit Paris" Participant 5. Source: photograph of Participant 5

Thirdly, although organized activities and travelling were important elements, pictures that illustrated 'lazy' afternoons were also very 
prominent in the set of pictures. One participant explicitly mentioned that "you can really enjoy just staying one day lying on the ground doing nothing" (Participant 4). It insinuates that a good day of being abroad was not necessarily filled with activities and trips. One last item of engaging in activities was the possibility of discovering new hobbies. Living in a foreign environment gave the participants the chance, place, and time to create and develop interests and passions, such as cooking and photography.

Obstacles. It was reported that keeping up to date with news from the local communities was challenging. Participant 1 argued that the Buddy Program was an effective mean to help overcome this obstacle.

\section{Bureaucracy}

Bureaucracy is "the type of organization designed to accomplish large-scale administrative tasks by systematically coordinating the work of many individuals" (Blau \& Meyer, 1971, p. 1).

\section{Opportunities}

Two participants shared pictures related to the bureaucracy in Belgium. Perceived as an opportunity to see how things were running in Belgium, bureaucracy was received with mixed feelings because participants were generally used to things arranged in a more informal way as in their home countries ( 2 out of 5 ).

\section{Obstacles}

Two aspects related to the bureaucratic complexity were recognized as obstacles. Firstly, the communication was perceived as more impersonal: much work had to be done via computers. This was seen as a challenge, particularly for Participant 2: "when I came here to Belgium, KU Leuven, I found that everything needs to be processed via computers. So you don't see faces. You are not talking to people, you are talking to computers" (see Figure 3). Subsequently, being not proficient in working with a computer could be an obstacle to gather necessary information (2 out of 5). Secondly, the administration was very complicated. One student struggled with the fact that he was sent from one office to another several times, without getting clear answers (see Figure 4).

Figure 3. Life without Faces. Source: photograph of Participant 2

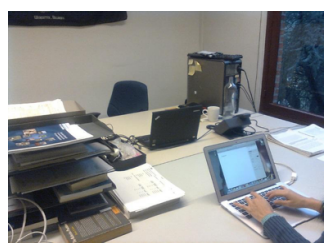


Figure 4. Bureaucracy. "I had to go to the office a thousand times and each time I was told a different thing. They couldn't give me an agreement."- Participant 1. Source: photograph of Participant 1.

\section{Transport}

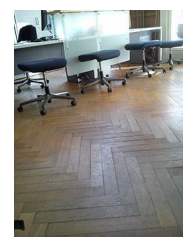

All participants sent in pictures that related to the biking culture and the scarcity of cars in the public domain. Below, an overview of a selection of pictures featuring bikes is given (see Figure 5-9).
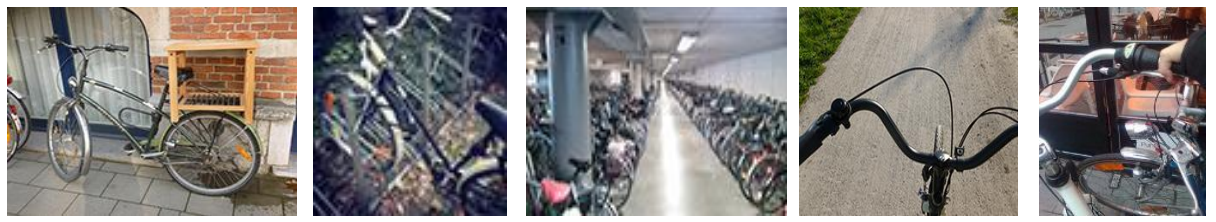

Figure 5-9. Source: photographs of all participants.

\section{Opportunities}

Biking was regarded as an opportunity to change the daily habit. It is experienced as a sportive and environmental-friendly means of transport. Almost everyone was used to driving a car back home. Because of the exposure to the biking culture in Leuven, participants experienced a change in their habit. Some of them even stressed that it led to a change in their mindset: they intended to keep this habit back in their home countries and continue biking (2 out of 5).

\section{Obstacles}

In contrast with the change of habit and mindset, the negative aspects of biking were also highlighted. For some participants biking was considered as inconvenient to their daily routines (3 out of 5). One participant said: "I love driving and I really miss my car. It could be helpful for going to the supermarket." Besides, it was not comfortable to use a bike in bad and cold weather.

\section{Food and Drinks}

The theme of food and drinks was very dominant in the visual displays of the participants. We combined twelve pictures illustrating this theme (see Figure 10-21). 


\section{Opportunities}

Food and drinks offered many opportunities to participants. Firstly, trying out new food and drinks from different cultures was experienced by all participants as a nice way to learn about cultures. For example, students drank Belgian beer to become familiar with the Belgian beer culture. Secondly, food and drinks provided a medium to meet new friends. Participants went frequently for 'just a drink' with friends in local pubs. Thirdly, some participants mentioned that consuming food and drinks from their home countries was experienced as balm to deal with feelings of homesickness.

\section{Obstacles}

It was not always easy to find food and drinks from home countries ( 3 out of 5). Some of them counted on friends who brought it, and others went to specific cultural supermarkets. As for the local food, a discrepancy between perception and behavior was recognized. Though the local food was perceived by the participants as quite unhealthy, it was still favored by the participants. For instance, Alma (student restaurant) not only offered fried fries, it also provided other healthier supplements (rice and mashed potatoes). Despite the existence of these options, participants preferred the unhealthy takeaway food. When looking at the series of pictures of food and drinks (see Figure 10-21), we spotted a variety of takeaway food plates. As Participant 4 said: "If I tell my mother that I go to Alma and eat a half plate of French fries, she will become crazy".

Figure 10-21. Source: photographs of Participant $1,3,4,5$

\section{Language}

\section{Opportunities}
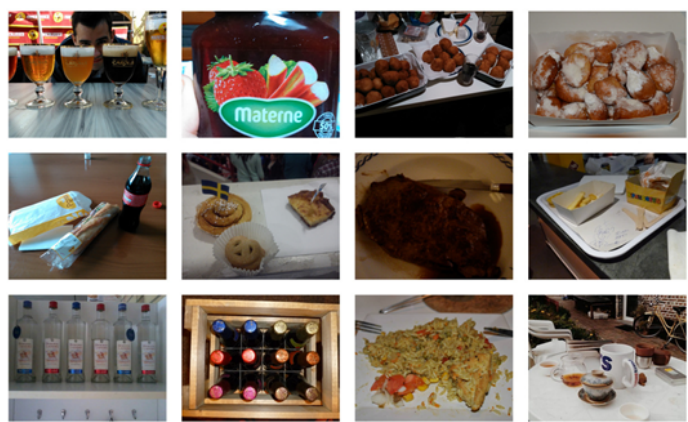

The language study was seen as a medium and opportunity to gain insight in the local culture. Three participants said that they rarely experienced difficulties with communicating in English. Two participants started to take Dutch courses as a way to get to know the local culture in more depth, whereas other participants only dealt with English. 


\section{Obstacles}

The local language posed a challenge: "It is challenging to live in a country without knowing the official language" (Participant 1). Some announcements could not be understood, for instance an announcement at a bus stop (see Figure 22) or the labels on the products in the supermarket. In such cases, mastering English was not sufficient.

Figure 22. Public Utility. Source: photograph of Participant 1.

\section{Environment}

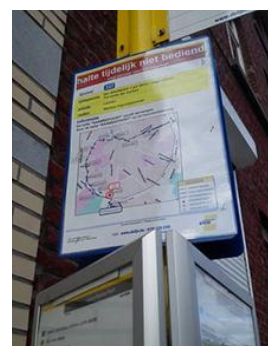

Environment-related issues are understood as weather conditions, impact of the seasons, specific local surroundings, parks and nature domains.

\section{Opportunities}

The chance to experience four seasons was something new for South American students, because "the change of the summer, winter, autumn, spring in Brazil is not clear" (Participant 5). Correspondingly, one picture was even called "Understand why the great authors fell in love with fall" (Participant 4, see Figure 23). It was an extra benefit for the participants ( 3 out of 5 ) that the nature was close to the city. It created a relaxing atmosphere and a nice opportunity to "see the beauty in everything" (Participant 3).

Figure 23. Understand Why the Great Authors Fell in Love with Fall. Source: photograph of Participant 4.

\section{Obstacles}

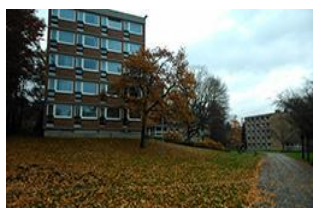

Bad weather could prevent students from carrying out their daily routines. Four participants saw the local weather conditions as an obstacle to do things and to venture outside. The unexpected pattern of rain often resulted in a bad mood for two participants. They had to carry an umbrella or a rain coat at all times to protect against possible weather changes, which they were not used to. It made them realize that the amount of sunshine from home countries was not at all self-evident in the local city ( 2 out of 5 ). 


\section{Academic Challenges}

Academic challenges mainly related to teaching and learning in official school settings (such as offices, auditoriums, and campus sites), internships, courses, homework, and exams.

\section{Opportunities}

An opportunity of studying abroad was the chance to study or work together with different nationalities in the context of teamwork (see Figure 24). This 'forced' them to go into debates and discussions, which was something they appreciated ( 2 out of 5). Another benefit reported was the possibility to become familiar with a new educational system emphasizing more on the theoretical aspects of knowledge and organizing exams in both written and oral forms. This was very different from that of their home countries.

Figure 24. You Can Meet a Lot of New Cultures. "I just entered the auditorium and I saw a lot of people and I thought, I need to take a picture. This is huge." - Participant 4. Source: photograph of Participant 4.

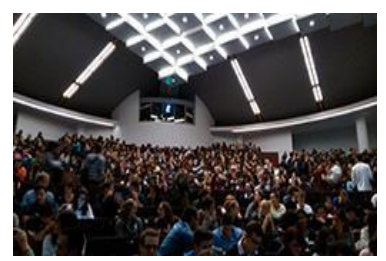

\section{Obstacles}

The different educational and evaluative styles of the host university and the instructional language English caused stress and required an adjustment in studying ( 2 out of 5). Moreover, homework posed a challenge for two participants in terms of balancing academic and leisure time.

\section{Psychological Challenges}

Psychological challenges refer to challenges from processes in behavior and mind (Brysbaert, 2008). They are often associated with psychological distress due to adaptation stress and different values (Constantine et al., 2004; Russell et al., 2010).

\section{Opportunities}

Encountering different values from the local culture and other international cultures was exciting for the participants (4 out of 5). One example of such value was the high level of open-mindedness (see Figure 25). In South America, the perception towards gay people is different from 
that of Belgium: only one country in South America allows gay marriages, namely Argentina (Barrionuevo, 2010). Being confronted with different values, some participants started to reflect on their own values. Participant 3 said: "Now I am realizing that I'm sometimes in the middle of [the value systems of] South America and Europe. But in many aspects mine are closer to European values." Sometimes the confrontation with European values led the participants to appreciate their patriot values more. Two participants missed the kind of hospitality shown in their home country, which they did not find in Belgium.

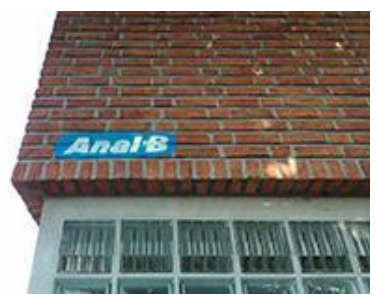

Figure 25. Street Art Can Teach You How the Culture is Open-Minded. "You cannot be so open-minded in Brazil because the culture holds you back. [...] I am gay. So in Brazil you cannot say, like my parents don't know. [...] Here I can really be myself." - Participant 4. Source: photograph of Participant 4.

\section{Obstacles}

The confrontation with the local culture, values, and habits made four participants uncomfortable. For instance, parents in Belgium were seen as too tolerant towards their children's behavior, giving them too much freedom (see Figure 26). In comparison, the parenting style in South America is characterized by horizontal collectivism, strictness, and frequently practices of physical punishment (Chang \& Liou, 2009).

Figure 26. Kids Can Do Dangerous Things Here and Their Parents Will Just Say It Is Okay. Source: photograph of Participant 4.

Another difficulty in dealing with local cultural values was that they felt a discomfort due to not knowing how to act 'right', which

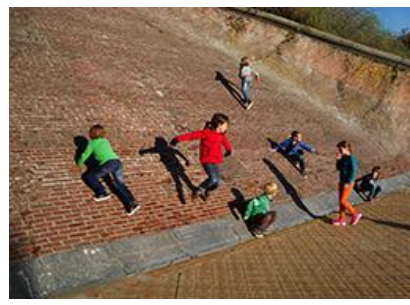
prevented them from behaving natural (see Figure 27). Over time, these feelings of discomfort were reduced because of a better understanding of the local behavioral patterns. Friends were perceived as an important element to overcome these obstacles ( 2 out of 5 ). 


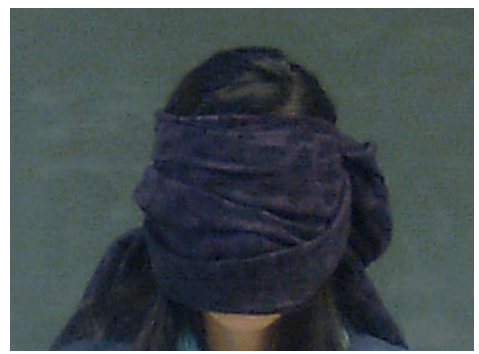

Figure 27. Play Blind, Deaf, Mute. "The fact that you are taken out of your own context and put into a new context. You have to open your eyes and you are still blind. You listen, but you are still deaf. You say things, but you are still mute. So that is the challenge I think, to move away from where you are." - Participant 2. Source: photograph of Participant 2.

Prevailing stereotypes were a last obstacle they had to overcome. Some were worried about stereotypes related to their home countries; some wanted to prove that these stereotypes were wrong and change local people's perceptions ( 2 out of 5). Participant 4 stated that "I wanted to sell the idea that I am not lazy. It was for me the challenge."

\section{DISCUSSION}

At the end of this study, we return to our first research question - what are the challenges that contribute to or hinder the adjustment experiences of international students? The presented challenges relate to three main themes: socio-cultural, academic, and psychological challenges. Socio-cultural challenges can be further divided into social interaction, engaging in activities, bureaucracy, transport, food and drinks, language, and environment. The challenges inherent in students' life abroad are labelled as situational variables (same as in-sojourn factors). Challenges are discussed in terms of opportunities that contribute to adjustment and obstacles that hinder adjustment.

According to the model put forward by Schartner and Young (2016), adjustment will lead to adaptation. However, we do not consider successful adaptation the only potential outcome here. Depending on their level of adjustment, different people may end up on different sides of a continuum between full adaptation and maladaptation. To answer the second research question on pathways international students' may potentially follow, we refined the model from Schartner and Young (2016) by integrating the findings from this study and Berry's (1997) theory in acculturation, and developed a new model (see Figure 28). Berry's acculturation theory describes an immigrant individual's acculturation strategies. According to Berry (1997), people adopt one of the following 
four strategies in adjustment: integration, assimilation, separation, and marginalization. Integration means adapting the cultural norms of both host and home countries. Assimilation is when an immigrant adopts the cultural norms of the host society and abandons those of his/her home country. If an immigrant keeps the original culture, but rejects the local culture, this person is engaged in a separation strategy. If someone rejects the norms of both cultures, he/she adopts a marginalization acculturation strategy. It is assumed that an integration or assimilation strategy will move students towards an adaptation mode, while a separation or marginalization strategy might lead students into a maladaptive mode.

International students may adopt different acculturation strategies based on their adjustment experiences. This is in line with the findings from a previously conducted study with Asian students (Wang \& Hannes, 2014). For example, being exposed to the local biking culture has changed participants' mindset as well as their actual behavior, with some starting to use a bike more often. Preferred means of transportation are relatively easy to change and participants tend to adopt an integration or assimilation strategy in these types of situations. Encountering a more abstract layer of cultural habit though, for example differences in hospitality and parenting styles could make international students quite uncomfortable. These cultural habits relate to deeply held values on a societal level. Participants were less willing to change their own values on these issues with some adopting a separation acculturation strategy.

While international students may initially experience certain aspects as negative, we believe that these discomforts may also create additional learning potential (McLeod \& Wainwright, 2009; Wang \& Hannes, 2014). It is precisely these moments that offer opportunities from the perspective of 'pedagogies of discomfort'. This type of pedagogy invites critical thinking, awareness raising, re-appreciating of one's own culture, and re-evaluating worldviews (Boler \& Zembylas, 2003). There is a benefit from moving out of the comfort zone, to situations in which emotional, unconscious daily habits and values become questioned (Boler \& Zembylas, 2003). To deal with issues of discomfort, intercultural dialogue and cooperation between students from multiple cultures including local students could be organized to deepen their intercultural understandings and cultivate their multicultural competence (Zhao \& Wildemeersch, 2008). 


\begin{tabular}{l}
\hline INDIVIDUAL \\
VARIABLES: \\
language ability, \\
personality, cultural \\
intelligence, \\
emotional \\
intelligence, \\
knowledge about the \\
host country, prior \\
overseas experience, \\
etc. \\
SITUATIONAL \\
VARIABLES \\
- Social interaction \\
- Engaging \\
activitics \\
- Bureaucracy \\
- Transportation \\
- Foodand drinks \\
- Language \\
- Environment
\end{tabular}

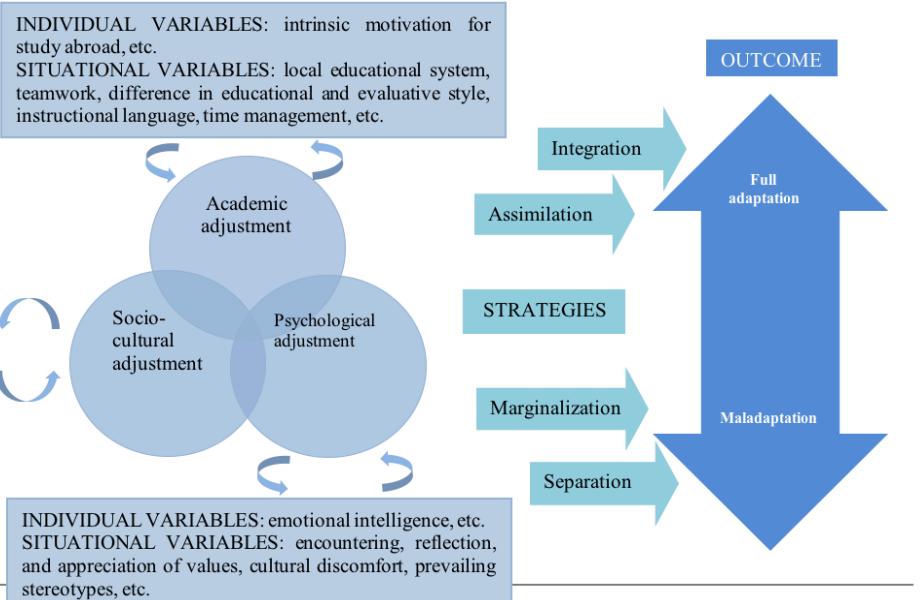

Figure 28. A Refined Model of International Student Adjustment and Adaptation.

The adjustment process may involve a period of transformation of students. This study shows that the pre-sojourn factors, or what are called individual variables in this study, are dynamic. For example, students develop their cultural empathy as they adjust to the foreign context. Being confronted with the local culture stimulates a reflection and reinterpretation of international students' own cultural frameworks (Church, 1982).

This is in line with Brown's (2009) insight on the transformative potential of being exposed to a new culture. It leads to an advancement of one's cross-cultural understanding, an opportunity for self-discovery and eventually, a change of self. An example illustrating the process of learning to appreciate the local culture was the openness towards the minorities, especially the gay population. 'Being gay' was experienced as relatively more tolerant by the local population compared with that from participants' host countries. It made international students realize that a different attitude towards minorities was a possibility. There are important differences between participants in how they experience and report on the challenges. For instance, there is one participant who mentioned more obstacles than opportunities, another participant on the other hand, kept seeing positive sides in all of the challenges reported. 
This is a consistent with a finding from previous conducted research (Wang \& Hannes, 2014) wherein the result suggests that a successful integration is dependent on the personal characteristics and individual coping mechanisms. Participants who were more inclined to a separation strategy echoing a 'tourist-attitude', reported more obstacles and sought for solutions within their own culture framework. By contrast, those who appeared to be more open to an integration strategy, expressed more opportunities than obstacles. Second possible explanation relates to the difference in students' coping mechanisms. Some students will cope with difficulties by maladaptive coping strategies (emotional control and suppression) during their study period abroad. For these students, the stress in the initial phase is not removed by a longer exposure to the new study setting. This may result in negative consequences, such as symptoms of depression, segregation, or perceived stress (Smith \& Khawaja, 2011). Their student life abroad is more negatively evaluated. Others make use of adaptive coping mechanisms by accepting and reinterpreting things positively. They take risks motivated by the will to get adjusted. This correlates with more positive happenings (Hendrickson, Rosen, \& Aune, 2011; Mcleod \& Wainwright, 2009; Ward, Bochner, \& Furnham, 2001).

\section{Limitation and Implications}

For this study, we included an estimate of the number of participants supporting a particular statement in the narrative, not with the purpose to provide indications of which themes were most relevant, but in an attempt to provide a more realistic picture of ideas that were shared and those that were more deviant. Frequencies are indeed limited in the sense that they tell us nothing about the intensity with which a particular theme was brought by someone or how it had been expressed or voiced (Hannes, 2009). This should be taken into account when interpreting the findings and judging the examples we used to refine Schartner and Young's (2016) model.

The limitation of this study is related to the use of English language. We used English as the main language of communication for pragmatic reasons - this was the language shared by researchers and participants. It was cost saving, in the sense that we did not have to hire external interviewers who master the mother tongues of the participants or involve interpreters in the analytical phase. However, this explicit choice put our 
participants in a vulnerable position: they had to communicate in a language that was imposed on them. We knew from previously conducted studies (Swarts, 2012; Wang \& Hannes, 2014) that for some participants the lack of command of English vocabulary would lead to difficulties in fully expressing themselves and fully engaging in group discussions. People who have a better command of English language could weigh more in the discussions. This is one of the main reasons why we decided to follow-up with individual interviews instead of focus groups, as it would give them more time to think and phrase their thoughts.

The South American countries represented in this study sample were limited to three countries: Brazil, Peru, and Ecuador. We noticed, however, that attitudes on the exchange experiences and coping mechanisms were not directly associated with country of origin, but rather with the individual characteristics of particular students. This has also been found in previously conducted study (Wang \& Hannes, 2014). This finding suggests that the refined model would apply to a variety of different international student groups. We invite colleague researchers to test this claim by putting the framework to use in their own studies on acculturation processes of international students. Follow up studies could also focus on the specific inter-group and individual factors' contribution to international students' perceptions of acculturation challenges, or how such differences may play a role in these perceptions.

\section{CONCLUSION}

In this photo elicitation project featuring the adjustment experiences of South American students in Flanders, three main themes are identified: socio-cultural challenges, academic challenges, and psychological challenges. The situational and individual variables identified on the presojourn and in-sojourn level dynamically interact with adjustment process, leading to different levels of adaptation for international students. One of the more interesting patterns discovered is that an encounter with cultural values of the host society seems to push some students in a reflective mode. This illustrates that some experiences of discomfort may create learning potentials. The role of individual characteristics versus group characteristics as a potential determinant in the different pathways described should further be explored. 


\section{ACKNOWLEDGMENT}

We would like to acknowledge the effort and contributions of the students who participated in this study. We are also sincerely grateful to the anonymous reviewers for providing very insightful feedback on the manuscript.

\section{REFERENCES}

Altbach, P. G., \& Engberg, D. (2014). Global student mobility: The changing landscape. International Higher Education, (77), 11-13. doi:10.1016/01436236(82) $90038-2$

Barrionuevo, A. (2010, July 15). Argentina approves gay marriage, in a first for region. The New York Times. Retrieved from http://www.nytimes.com/ 2010/07/16/world/americas/16argentina.html?_r=0

Berry, J. W. (1997). Immigration, acculturation, and adaptation. Applied Psychology, 46(1), 5-34. doi:10.1111/j.1464-0597.1997.tb01087.x

Blau, P. M., \& Meyer, M. W. (1971). Bureaucracy in modern society. New York, NY: Random House.

Boler, M, \& Zembylas, M. (2003). Discomforting truths: The emotional terrain of understanding difference. In P. P. Trifonas (Eds.), Pedagogies of difference: Rethinking education for social justice (pp.107-130). London: Routlegde.

Brown, L. (2009). The transformative power of the international sojourn: An ethnographic study of the international student experience. Annals of Tourism Research, 36(3), 502-521. doi:10.1016/j.annals.2009.03.002

Brysbaert, M. (2008). Fundamenten van de psychologie. Gent: Academia Press.

Chang, N. Y., \& Liou, T. Y. (2009). A study of Latino parenting culture and practices: Listening to the voices of Latino parents. Hsiuping Journal of Humanities and Social Sciences, 12, 1-36. Retrieved from http://ir.hust.edu.tw/dspace/bitstream/310993100/1599/1/1201.pdf\#page $=1 \&$ zoom $=$ auto, $-151,451$

Church, A. T. (1982). Sojourner adjustment. Psychological Bulletin, 91(3), 540572. doi: 10.1037/0033-2909.91.3.540

Collier, J. (1957). Photography in anthropology: A report on two experiments. American Anthropologist, 59(5), 843-859. doi:10.1525/aa.1957. 59.5.02a00100

Constantine, M. G., Okazaki, S., \& Utsey, S. O. (2004). Self-concealment, social self-efficacy, acculturative stress, and depression in African, Asian, and Latin American international college students. American Journal of Orthopsychiatry, 74(3), 230. doi:10.1037/0002-9432.74.3.230

Fritz, M. V., Chin, D., \& DeMarinis, V. (2008). Stressors, anxiety, acculturation and adjustment among international and North American students. 
International Journal of Intercultural Relations, 32(3), 244-259. doi:10.1016/j.ijintrel.2008.01.001

Guillen, P., \& Ji, D. (2011). Trust, discrimination and acculturation: Experimental evidence on Asian international and Australian domestic university students. Journal of Socio-Economics, 40(5), 594-608. http://dx.doi.org/10.1016/j.socec.2011.04.016

Hannes, K. (2009). Understanding the evidence-based movement: A context-specific study on obstacles to implementing 'evidence-based practice' (Doctoral dissertation). KU Leuven, Leuven, Belgium.

Hannes, K., \& Parylo, O. (2014). Let's play it safe: Ethical considerations from participants in a photovoice research project. International Journal of Qualitative Methods, 13(1), 255-274. Retrieved from http://ejournals.library.ualberta.ca/index.php/IJQM/article/view/21243/168 97

Harper, D. (2002). Talking about pictures: A case for photo elicitation. Visual Studies, 17(1), 13-26. doi:10.1080/14725860220137345

Hendrickson, B., Rosen, D., \& Aune, R. K. (2011). An analysis of friendship networks, social connectedness, homesickness, and satisfaction levels of international students. International Journal of Intercultural Relations, 35(3), 281-295. doi:10.1016/j.ijintrel.2010.08.001

Howitt, D. (2010). Introduction to qualitative methods in psychology. Harlow: Prentice Hall.

Kagan, H., \& Cohen, J. (1990). Cultural adjustment of international students. Psychological Science, 2, 133-137. doi:10.1111/j.14679280.1990.tb00082.x

Kolb, B. (2008). Involving, sharing, analysing-potential of the participatory photo interview. Forum: Qualitative Social Research, 9(3). Retrieved from http://www.qualitative-research.net/index.php/fqs/article/view/1155/2574

KU Leuven. (2017a). Why choose KU Leuven? Retrieved from https://www.kuleuven.be/english/why-choose-kuleuven.html

KU Leuven. (2017b). Personal buddy. Retrieved from http://www.kuleuven.be/studenten/buddy.html

Lee, J. J., \& Rice, C. (2007). Welcome to America? International student perceptions of discrimination. Higher Education, 53(3), 381-409. doi:10.1007/s10734-005-4508-3

Margolis, E., \& Pauwels, L. (Ed.). (2012). The Sage handbook of visual research methods. Los Angeles, LA: Sage.

McLeod, M., \& Wainwright, P. (2009). Researching the study abroad experience. Journal of Studies in International Education, 13(1), 66-71. doi: $10.1177 / 1028315308317219$ 
Mesidor, J. K., \& Sly, K. F. (2016). Factors that contribute to the adjustment of international students. Journal of International Students, 6(1), 262-282. Retrieved from https://files.eric.ed.gov/fulltext/EJ1083269.pdf

Organisation for Economic Co-operation and Development. (2015). Education at a glance 2015: OECD indicators. Paris: OECD. doi: 10.1787/76d4bc29-en

PennState College of Agricultural Sciences. (2007). Benefits of studying abroad. Retrieved from http://agsci.psu.edu/international/study-abroad/benefits-ofstudy-abroad

Rienties, B., Beausaert, S., Grohnert, T., Niemantsverdriet, S., \& Kommers, P. (2012). Understanding academic performance of international students: The role of ethnicity, academic and social integration. Higher Education, 63(6), 685-700. doi:10.1007/s10734-011-9468-1

Roberts, B. (2011). Photographic portraits: Narrative and memory. Forum: Qualitative Social Research, 12(2). Retrieved from http://www.qualitativeresearch.net/index.php/fqs/article/view/1680/3203

Russell, J., Rosenthal, D., \& Thomson, G. (2010). The international student experience: Three styles of adaptation. Higher Education, 60(2), 235-249. doi:10.1007/s10734-009-9297-7

Savin-Baden, M., \& Major, C. H. (2013). Qualitative research: The essential guide to theory and practice. London: Routledge.

Schartner, A., \& Young, T. J. (2016). Towards an integrated conceptual model of international student adjustment and adaptation. European Journal of Higher Education, 6(4), 372-386. http://dx.doi.org/10.1080/ 21568235.2016.1201775

Searle, W., \& Ward, C. (1990). The prediction of psychological and sociocultural adjustment during cross-cultural transitions. International Journal of Intercultural Relations, 14(4), 449-464. http://dx.doi.org/10.1016/01471767(90)90030-Z

Smith, R. A., \& Khawaja, N. G. (2011). A review of the acculturation experiences of international students. International Journal of Intercultural Relations, 35(6), 699-713. doi:10.1016/j.ijintrel.2011.08.004

Swami, V., Arteche, A., Chamorro-Premuzic, T., \& Furnham, A. (2010). Sociocultural adjustment among sojourning Malaysian students in Britain: A replication and path analytic extension. Social Psychiatry and Psychiatric Epidemiology, 45(1), 57-65. http://dx.doi.org/10.1007/s00127009-0042-4

Swarts, T. (2012). Obstacles and challenges in the adjustment processes of African students studying abroad: A photo voice research project. (Unpublished master's thesis). KU Leuven, Leuven, Belgium.

Tylor, E. B. (1871). Primitive culture: Researches into the development of mythology, philosophy, religion, language, art and custom. London: J. Murray. 
Van Hoof, J. V., \& Van Ruysseveldt, J. (Ed.). (2008). Sociologie en de moderne samenleving: Maatschappelijke veranderingen van de industriële omwenteling tot in de 21ste eeuw. Amsterdam: Boom.

Wang, C. C. D. C., \& Mallinckrodt, B. (2006). Acculturation, attachment, and psychosocial adjustment of Chinese/Taiwanese international students. Journal of Counseling Psychology, 53(4), 422-433. http://dx.doi.org/10. 1037/0022-0167.53.4.422

Wang, Q., \& Hannes, K. (2014). Academic and socio-cultural adjustment among Asian international students in the Flemish community of Belgium: A photovoice project. International Journal of Intercultural Relations, 39(1), 66-81. doi:10.1016/j.ijintrel.2013.09.013

Ward, C., Bochner, S., \& Furnham, A. (2001). The psychology of culture shock. Philadelphia, PA: Routledge.

Ward, C., \& Kennedy, A. (1993). Psychological and socio-cultural adjustment during cross-cultural transitions: A comparison of secondary students overseas and at home. International Journal of Psychology, 28(2), 129147. doi:10.1080/00207599308247181

Wei, M. F., Heppner, P. P., Mallen, M. J., Ku, T. Y., Liao, K. Y. H., \& Wu, T. F. (2007). Acculturative stress, perfectionism, years in the United States, and depression among Chinese international students. Journal of Counseling Psychology, 54(4), 385-394. http://dx.doi.org/10.1037/0022-0167.54.4.385

Zhang, J., \& Goodson, P. (2011). Predictors of international students' psychosocial adjustment to life in the United States: A systematic review. International Journal of Intercultural Relations, 35(2), 139-162. doi: 10.1016/ j.ijintrel.2010.11.011

Zhao, M., \& Wildemeersch, D. (2008). Hosting foreign students in European universities: International and intercultural perspectives. European Education, 40(1), 51-62. http://dx.doi.org/10.2753/EUE1056-49344

QINGCHUN WANG is a PhD student affiliated to the Social Research Methodology Group from the Centre for Sociological Research in the Faculty of Social Sciences, KU Leuven. Her research interest is in the development of qualitative research methods, mainly in the area of visual research methods. She currently plugs her methodological experiments into a series of studies on acculturation processes of international students. Email: qingchun.wang@kuleuven.be

STEFFANIE LEEN was a master student from the Faculty of Psychology and Educational Sciences, KU Leuven. She was involved in the data collection and analytical phase of this project. She is now working in a 
Flemish expertise center supporting vulnerable children, young adults, and their parents with school affairs and integration in society. Email: sleen@arktos.be

KARIN HANNES, PhD, is an associate professor at the Social Research Methodology Group from the Centre for Sociological Research in the Faculty of Social Sciences, KU Leuven. Her main research interest is in developing, applying, and refining approaches to qualitative evidence synthesis. She is co-convener of the Cochrane Qualitative and Implementation Research Group and authored several books on metasynthesis approaches. On a primary research level, she has been focusing on the use and further development of arts-based and multi-sensory research methods in the context of working with vulnerable populations. Email: karin.hannes@kuleuven.be

Manuscript submitted: October 13, 2016 Manuscript revised: October 19, 2017 Accepted for publication: October 29, 2017 